\title{
MATLAB and PSPICE Dynamic Model of Axial- Field Permanent-Magnet Motor
}

\author{
A.H. Al-Badi and A. Gastli
}

\author{
Department of Electrical Engineering, College of Engineering, Sultan Qaboos \\ University, P.O.Box 33, Al Khod 123, Muscat, Sultanate of Oman, \\ Email:albadi@squ.edu.om, Gastli@squ.edu.om.
}

\section{النموذج الديناميكي لامحرك الكهريائ ني المجل المغنلايسي المحوري بلستخدلم MSPICE و MATLAB}

\begin{abstract}
عبدا مالباهي و عال الفهملي
خلاصة : تشرح هذه الورقة النموذج الديناميكي للمحرك الكهربائي ذي المجل المغنلطيسي المحوري. يمكن لستخدلم هذا

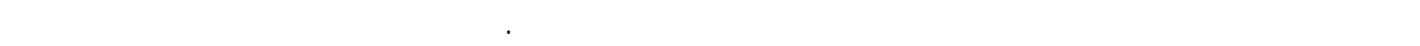
ووجد ظابق بين النتائج مما يثبت صحة البرة عند النموذج الديناميكي المستخدم.

ABSTRACT: In this paper a dynamic model of the axial-field, permanent-magnet machine will be discussed. The model may be used to study the transient response with the machine operating as a motor or as a generator. Experimental results are compared with Matlab/Simulink and Pspice predictions for a number of conditions, including the complete starting transient. Excellent correlation is obtained which validated both modeling approaches.
\end{abstract}

KEYWORDS: Torus Motor, Dynamic Model, Pspice and Matlab / Simulink.

\section{Introduction}

O ne of the important types of axial-field permanent-magnet machines is the Torus machine. A Torus machine is a double-sided, axial-field, disc-type, permanent-magnet, brushless d.c. motor. It is a compact lightweight machine, which offers significant advantages in application where space is restricted, due to its extremely short axial length. It has a simple toroidal, stripwound stator core that carries a slotless toroidal winding. The rotor comprises two discs carrying six axially polarised magnets. The disc rotors act naturally as fans, so even with high electric loading good cooling of the stator winding is obtained. High magnetic loading may be achieved using sintered Nd-Fe-B for the magnets. The Torus has very small stator leakage inductances and relatively small mutual inductances, because of the large effective air-gap compared with a conventional machine with slotted stator. The axial length of this machine can be made small, for a given power rating, because the active conductor length is the radial length of the stator winding, which falls between the rotor magnets. The axially directed end-winding lengths are relatively short, yielding low resistance compared with the end-winding resistance of a radial-field machine. Because of the geometry of the machine, the self-inductances and the mutual inductances between the stator phases are constant (independent of the rotor angular position). Some potential applications of Torus machines include auxiliary power unit, wind-power generator, electric vehicle, high speed generator driven by a gas turbine, adjustable-speed pump drive, lawnmower motor, etc.

Due to the complexity of the machine-drive systems and high switching frequency in the power electronics, the mathematical analysis and the experimental development are becoming difficult to perform as well costly and time consuming. The use of simulation is therefore strongly 
recommended so that the performance can be predicted and optimised before physically building the system. Pspice and Matlab are widely used by researchers and designers for the design and analysis of electric circuits and systems. They have been intensively used in the simulation of the performance of electrical machines and power electronic circuits (Al-Badi and Green, 1998, Chalmers et al 1997, Gastli et al 1998, Gastli and Akherraz, 1998, Green and Al-Badi, 1997).

\section{Mathematical Model}

\subsection{Circuit Equation Model}

The Torus motor has permanent magnets on the rotor and three stator windings. The equations of the motor can be expressed as follows:

$$
\left[\begin{array}{l}
V_{a} \\
V_{b} \\
V_{c}
\end{array}\right]=\left[\begin{array}{ccc}
R & 0 & 0 \\
0 & R & 0 \\
0 & 0 & R
\end{array}\right]\left[\begin{array}{l}
I_{a} \\
I_{b} \\
I_{c}
\end{array}\right]+p\left[\begin{array}{lll}
L_{a} & M_{a, b} & M_{a, c} \\
M_{b, a} & L_{b} & M_{b, c} \\
M_{c, a} & M_{c, b} & L_{c}
\end{array}\right]\left[\begin{array}{l}
I_{a} \\
I_{b} \\
I_{c}
\end{array}\right]+\left[\begin{array}{l}
e_{a} \\
e_{b} \\
e_{c}
\end{array}\right]
$$

where,

$R$ is the stator winding resistance $(0.133 \Omega)$.

$V_{a}, V_{b}, V_{c}$ are the phase voltages.

$I_{a}, I_{b}, I_{c}$ are the phase winding currents.

$e_{a}, e_{b}, e_{c}$ are the back emfs.

$L_{a}, L_{b}, L_{c}$ are the winding self inductances $(200 \mu \mathrm{H})$.

$M_{a, b}, M_{a, c}, M_{b, c}$ are the winding mutual inductances between the three phases $(73 \mu \mathrm{H})$.

$p$ is the mathematical differential operator $d / d t$.

\subsection{Electromagnetic Torque Model}

The electromagnetic torque $T_{\mathrm{e}}$ and the equations describing the mechanical response are:

$$
\begin{gathered}
T_{e}=\left(e_{a} I_{a}+e_{b} I_{b}+e_{c} I_{c}\right) / \omega_{m} \\
J p \omega_{m}=\left(T_{e}-T_{l}-B \omega_{m}\right) \\
p \theta_{m}=\omega_{m} \\
p \theta_{r}=P \omega_{m}
\end{gathered}
$$

where,

$T_{e}$ is the electromagnetic torque.

$T_{l}$ is the load torque.

$J$ is the moment of inertia of the rotating mass $\left(0.065 \mathrm{Kg} \mathrm{m}^{2}\right)$.

$P$ is the pole pair number.

$B$ is the damping constant $[0.00467 \mathrm{Nm} /(\mathrm{rad} / \mathrm{s}]$.

$p$ is the differential operator.

$\omega_{m}$ is the rotor speed in mechanical $\mathrm{rad} / \mathrm{s}$.

$\theta_{m}$ is the angle defining the rotor position in mechanical radians.

$\theta_{r}$ is the angle defining the rotor position in electrical radians.

\section{The Back EMF Model}

The back emf waveform is trapezoidal in shape, hence the transformation to $\mathrm{d}$, $\mathrm{q}$ axis reference frame can not be easily accomplished. Therefore, the a, b, c phase model will be used. 


\section{MATLAB AND PSPICE DYNAMIC MODEL}

For the test machine with high-field magnets and air-gap winding, the effective air-gap length is constant.

The measured back emf for a particular speed $(104.72 \mathrm{rad} / \mathrm{s})$ is represented in Figure 1. A Fourier analysis was performed on the waveform and values of the Fourier coefficients up to $37^{\text {th }}$ harmonic are considered (Al-Badi and Green, 1998).

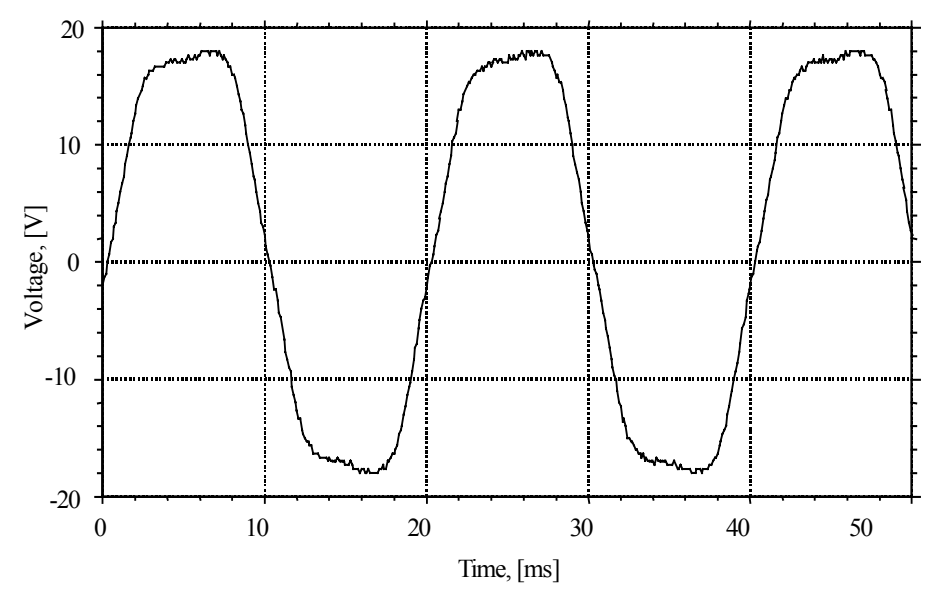

Figure 1. The back emf.

The initial model included coefficients up to $71^{\text {st }}$ harmonic but this was found to have a negligible effect on the shape of the waveform. The Fourier series for the back emf of phase a is given as:

$$
e_{a}=\frac{\omega}{\omega_{1}}\left[e_{1} \sin \left(\omega t-\phi_{1}\right)+e_{3} \sin \left(3 \omega t-\phi_{3}\right)+e_{37} \sin \left(37 \omega t-\phi_{37}\right)\right]
$$

Similar expressions can be obtained for the other two phases after including the appropriate phase shifts $\left(-120^{\circ}\right.$ for phase $b$ and $-240^{\circ}$ for phase c).

The Fourier coefficients $\mathrm{e}_{1}, \mathrm{e}_{3}, \ldots, \mathrm{e}_{37}$ are known for the particular speed $\omega_{1}$. Fourier coefficients can be calculated at any speed using the following back emf-speed relationship:

$$
\frac{e_{i}^{\prime}}{e_{i}}=\frac{\omega^{\prime}}{\omega}
$$

\section{Pspice Model for the Motor Drive System}

Figures 2, 3 and 4 show the 3-phase Torus motor system model, torque model, speed and position models respectively, that were developed using Pspice. The description of the full model was reported in (Al-Badi and Green, 1998). The resulting model is used to perform a comprehensive analysis of the system including the determination of the motor phase currents, line voltages, speed and electromagnetic torque.

\section{Matlab/Simulink Model}

A computer model of the 3-phase Torus motor system was also developed using the Matlab/Simulink software. Figure 5 shows the whole drive system with the inverter and the motor. The description of the full model is reported hereafter. The resulting model was used to perform a detailed analysis of the system including the determination of the motor phase currents and line voltages. 


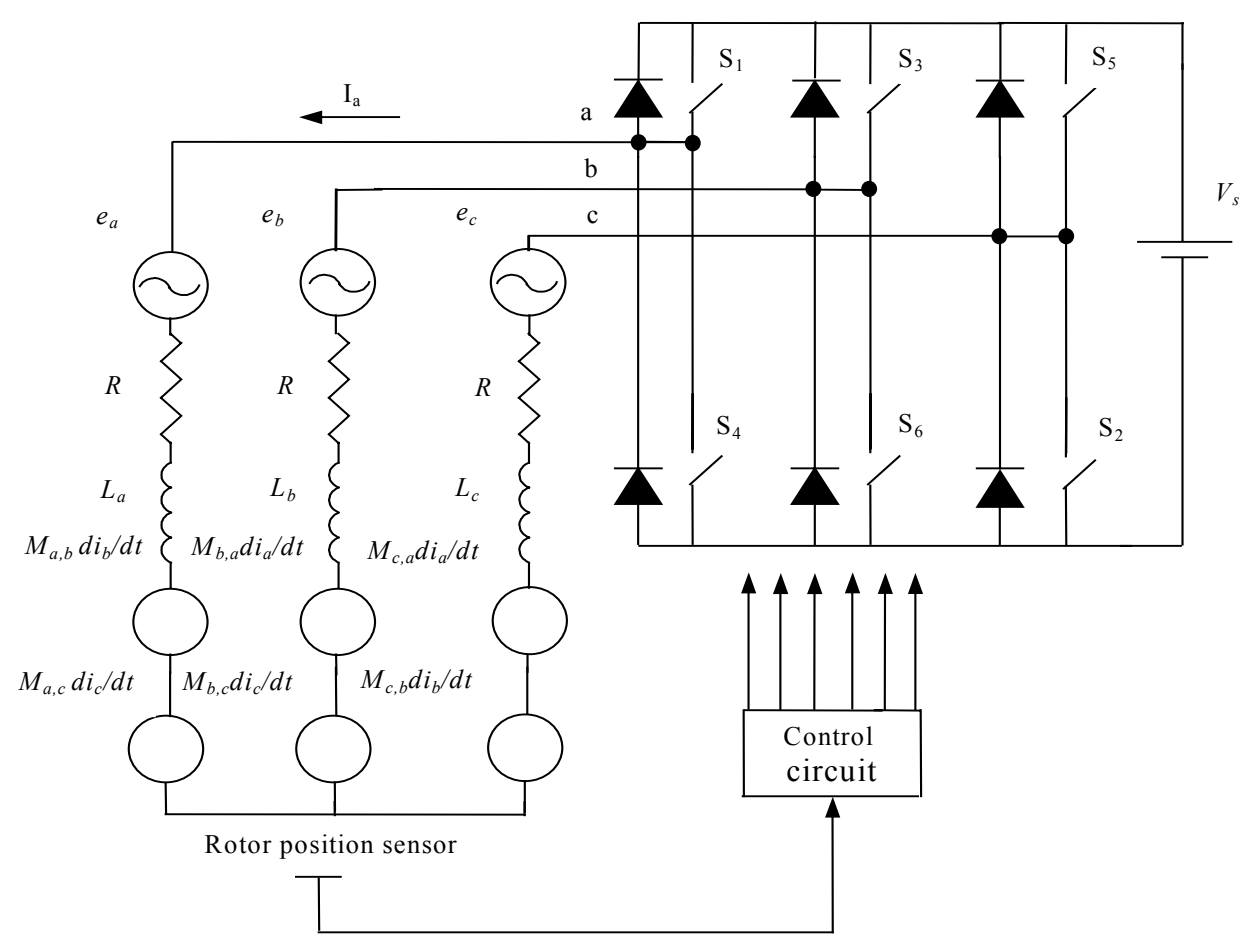

Figure 2. Circuit diagram for the drive system.

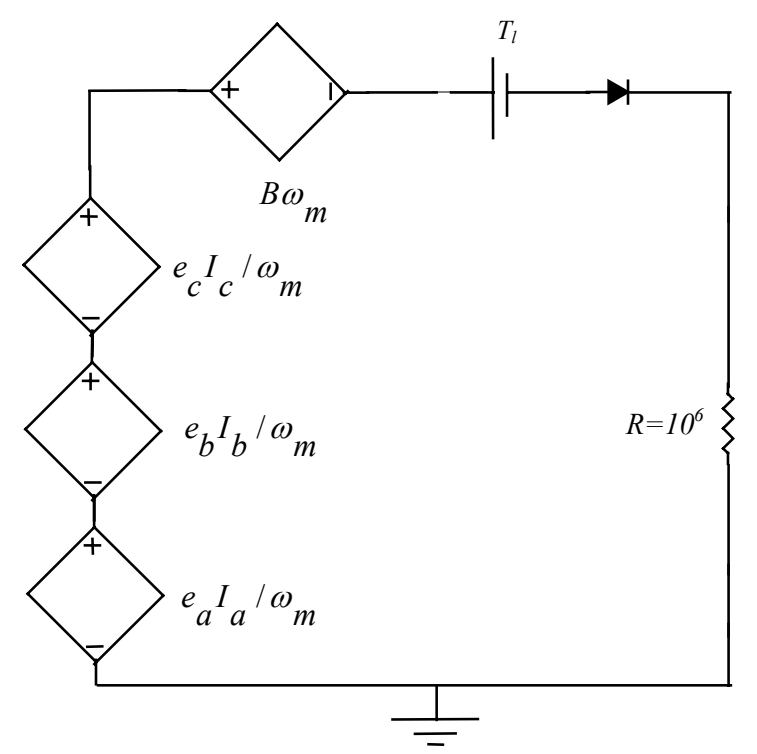

Figure 3. Torque circuit, $1 \mathrm{Nm} / \mathrm{V}$.
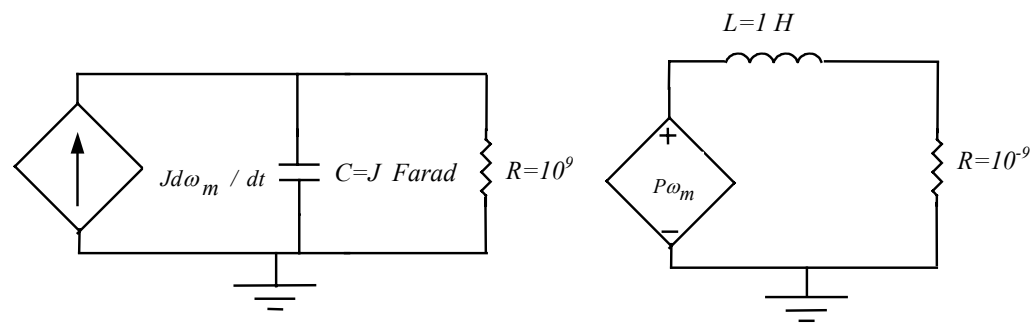

Figure 4. Speed circuit $\left(\omega_{m}\right), 1 \mathrm{rad} / \mathrm{s} / \mathrm{V}$ and position circuit $\left(\theta_{r}\right)$, electrical. 


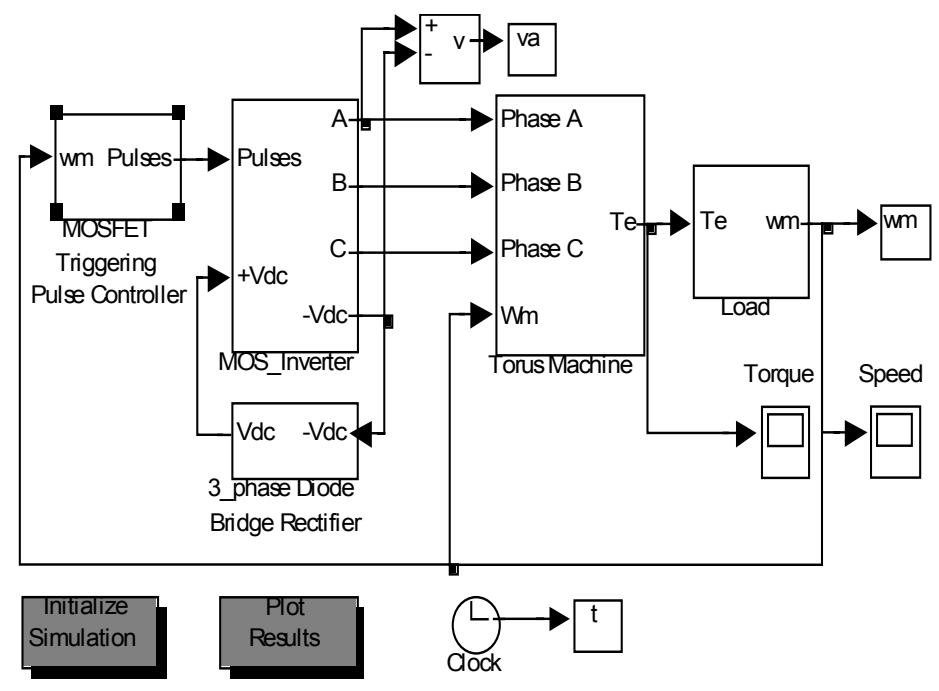

Figure 5. Torus motor drive system implemented with Simulink

\subsection{Machine Model}

The Torus machine model described by (1) can be easily implemented with Simulink blocks after separating the machine parameters matrix and the back emf model.

\subsubsection{Machine Parameters}

Figure 6 shows the model of the Torus machine. The machine windings consist of three-phase R-L circuits with self-inductances and mutual inductances. This three-phase circuit can be implemented with the Mutual Inductance block build in the Power System Blocksets library. The Mutual Inductance block implements a magnetic coupling between three separate windings. The self-resistance and inductance of each winding are specified on the first three entries of the dialog box and the mutual resistance and inductance in the last entry.

\subsubsection{Back emf}

The back emf was modeled for the three phases using (4) and including the appropriate phase shift between phases. The implementation is done with Simulink Function block.

Figure 7 shows the block diagram of the implemented model. Note that, for each phase, (4) was divided into four parts: part one includes all the harmonics from $1^{\text {st }}$ to $9^{\text {th }}$, part two includes the sum of all harmonics from $10^{\text {th }}$ to $19^{\text {th }}$, part three includes all harmonics from $20^{\text {th }}$ to $29^{\text {th }}$ and part 4 includes all harmonics from $30^{\text {th }}$ to $37^{\text {th }}$. $\omega t$ is implemented using the integral block and integrating the electric angular velocity $\omega$.

\subsection{Inverter Model}

The inverter used was made of six power switches controlled with six synchronized pulse generators. The inverter configuration is shown in Figure 8 . The dc voltage supply to the inverter is generated using the three-phase ac-dc converter (rectifier) shown in Figure 9.

\subsubsection{Switch Model}

The power electronics switch was implemented using the MOSFET model, which is a block build in the Matlab Power System Bolckset. The MOSFET is a semiconductor device controllable by the gate signal $(\mathrm{g}>0)$ if its drain current $I_{d}$ is positive $\left(I_{d}>0\right)$. The MOSFET is connected in parallel with an internal diode that turns on when the MOSFET is reverse biased $\left(V_{d s}<0\right)$. The model is simulated as a series combination of a variable resistor $\left(R_{t}\right)$ and inductor $\left(L_{o n}\right)$ in series with a switch controlled by a logical signal $(\mathrm{g}>0$ or $\mathrm{g}=0)$. The MOSFET turns on when the drain-source voltage is positive and a positive signal is applied at the gate input (i.e. $g=1)$. The 
MOSFET block also contains a series $R_{\mathrm{S}}-C_{s}$ snubber circuit, which is connected in parallel with the MOSFET.

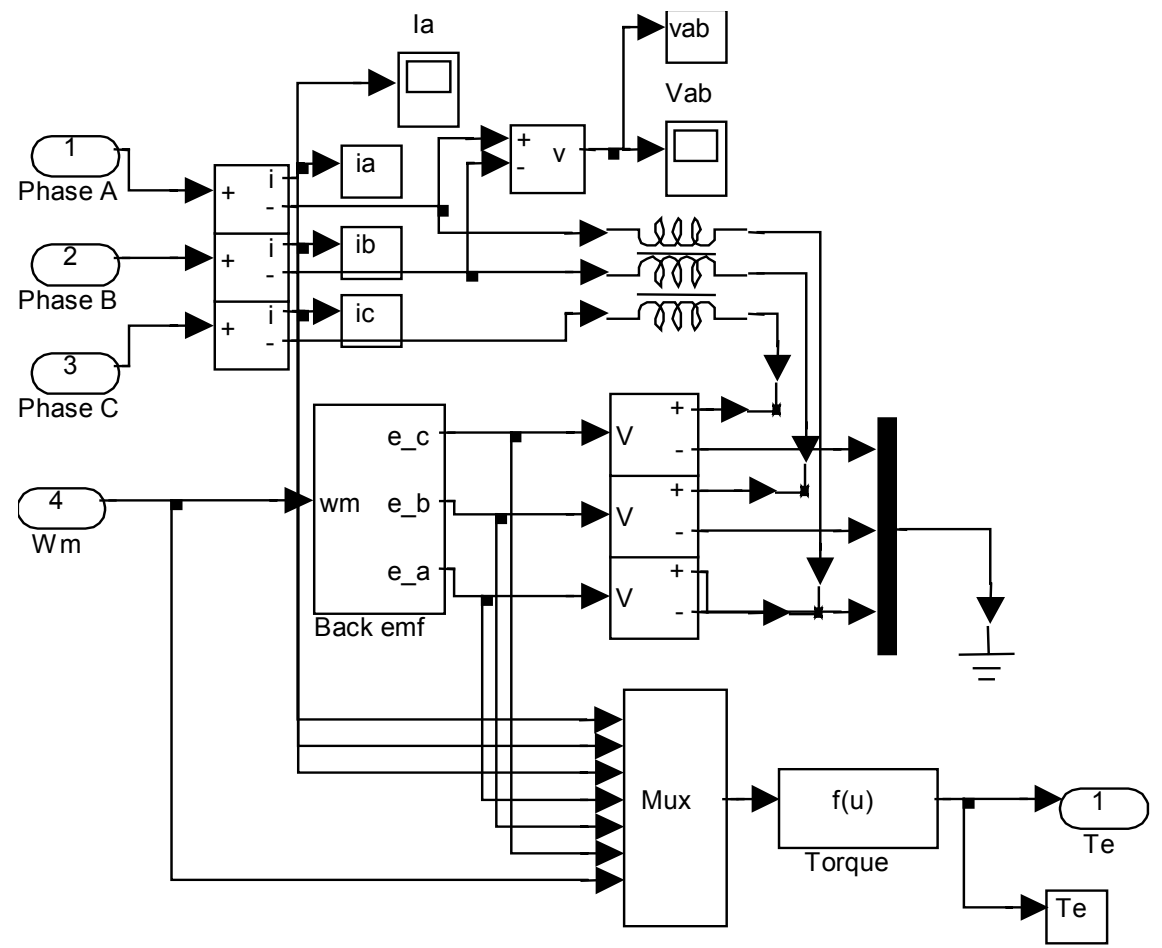

Figure 6. Torus machine model implemented with Simulink.

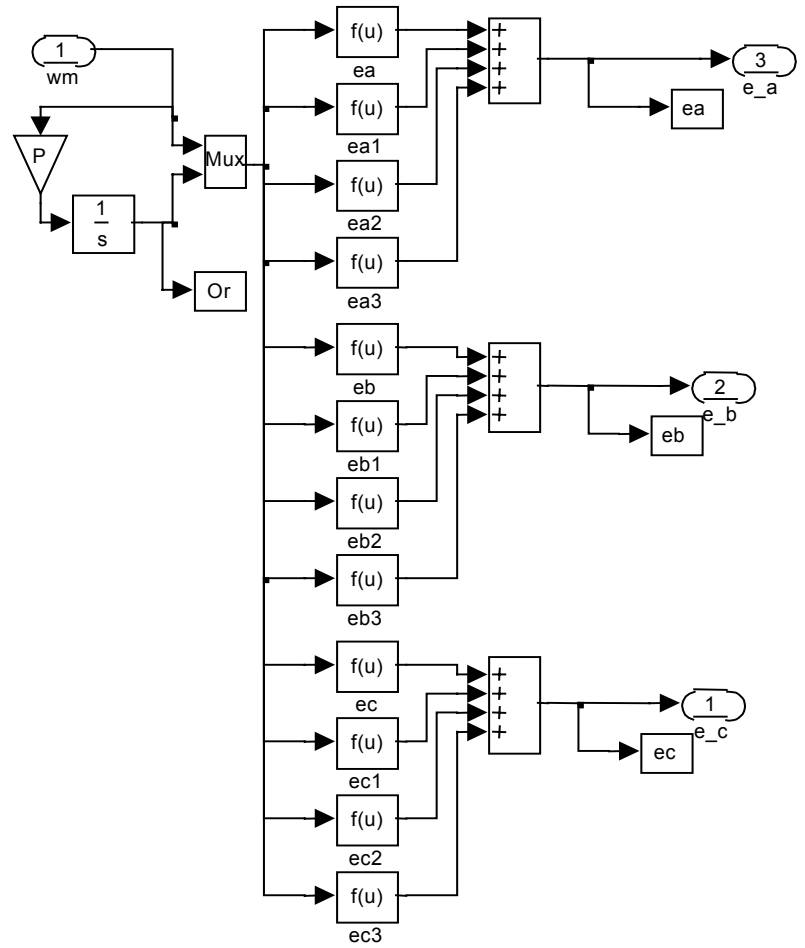

Figure 7. Back emf model implemented with Simulink. 


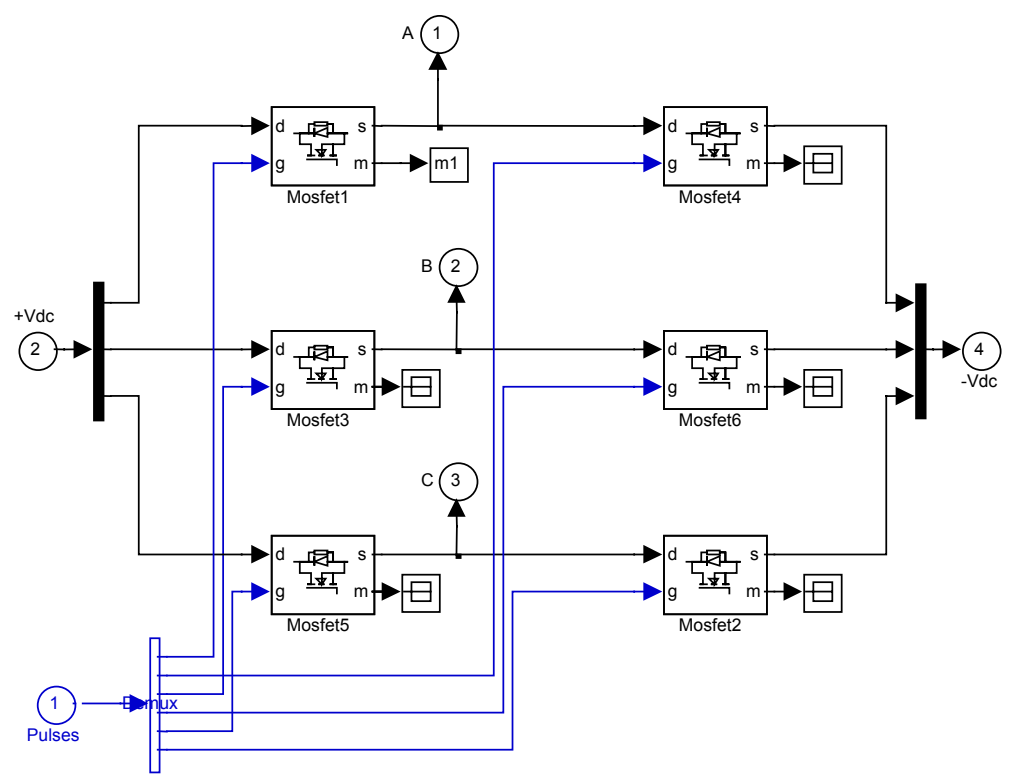

Figure 8. Inverter model implemented with Simulink

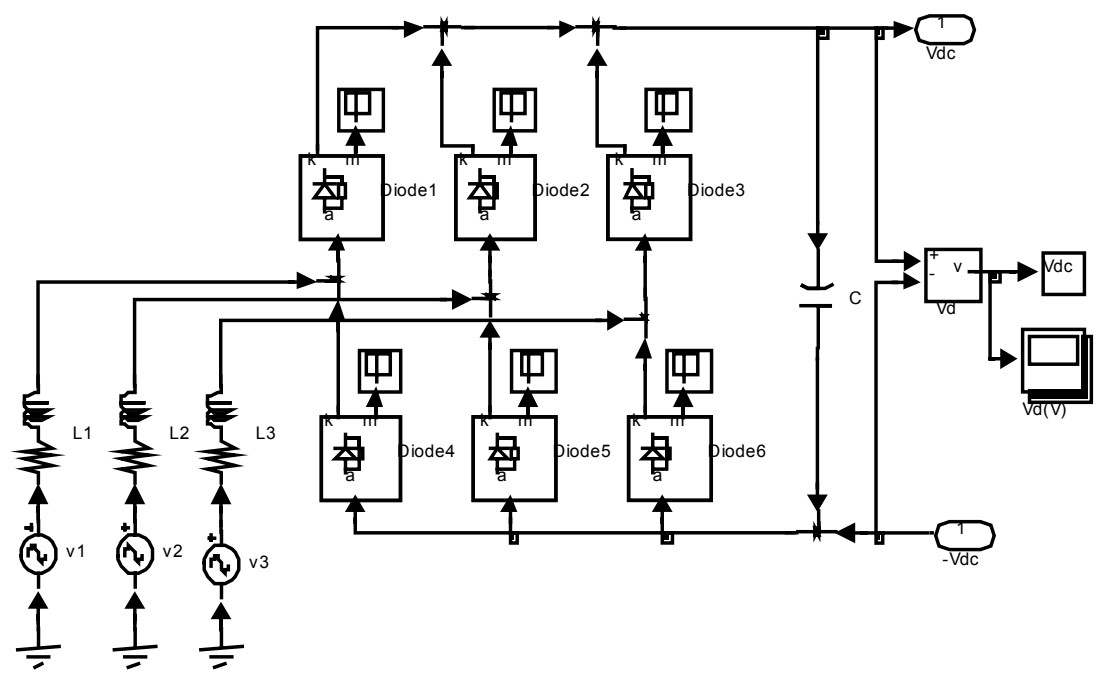

Figure 9. AC-DC converter circuit.

\subsubsection{Gate Signal Model}

The gate pulses for the six transistors were generated by six-pulse generator blocks taken from the built in Simulink library. The pulses period, duty cycle, and phases can be easily adjusted and set to desired values.

Figure 10 shows the block diagram of the model as it was implemented with Simulink blocks.

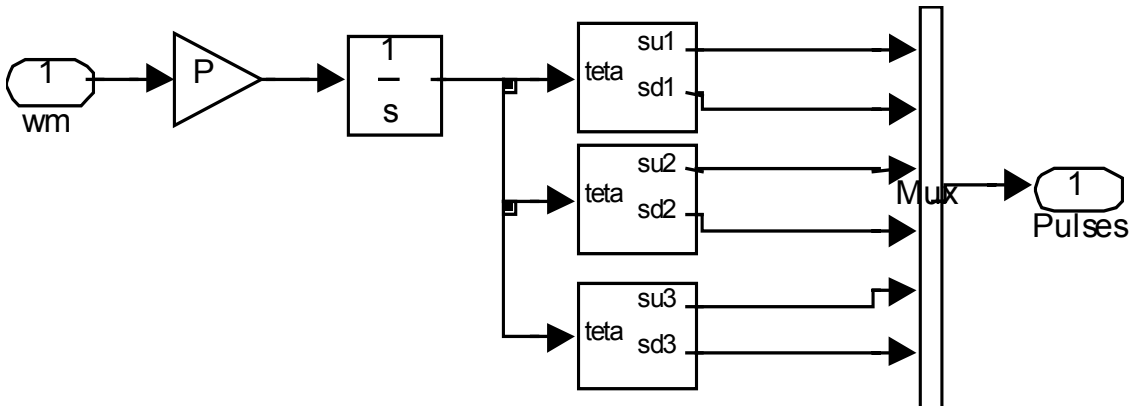

Figure 10. Gate signal model implemented with Simulink 


\section{Models Validation}

The validity of both models was verified by applying them to the prediction of the performance of the Torus motor drive system and comparing the simulation results with the corresponding experimental data.

\subsection{At Steady-State}

The dynamic model was first validated under steady state conditions by comparing simulated and measured phase current waveforms. Figures 11 and 12 show the simulated and measured phase current and line voltage waveforms at $40.5 \mathrm{~V}, 3.78 \mathrm{Nm}$. It indicated good correlation between the measured and simulated results.

\subsection{At Starting}

A $30 \mathrm{~V}$ rectified d.c. supply is applied across the inverter and then the switches are controlled on and off. The motor phase current and speed during starting and subsequent acceleration up to a final steady speed are shown in Figures 13 and 14. Figure 13 shows the experimental and simulated results of the current waveform during starting. Figure 14 shows the experimental and simulated speed build up during starting.

Closer examination of the current waveform shows that the peak current is determined almost by the circuit resistance because the inductance is very small, also evident in the finite rise in the phase current. The Figure shows also a spike superimposed on the top of each current pulse, owing to the switching which takes place every 60 degrees in other phases and to normal ripple in the rectified d.c. supply. The frequency of the first component is speed-dependent while the second is six times the a.c. supply frequency.

Comparison between measured and simulated results of the phase currents and speed waveforms shows good correlation between these results.

\section{Conclusion}

Dynamic performance prediction of an existing Torus motor drive system using Pspice and Matlab/Simulink models has been presented and compared with the actual drive performance. The two modeling approaches have been verified and validated with the experiments.

It is possible to conclude that both approaches provide satisfactory tools for the investigation of the axial-field machine drive system performance. They can be helpful in the design and analysis of any axial-field machine drive system, which includes the machine, the load, the converter and the controller. 
MATLAB AND PSPICE DYNAMIC MODEL

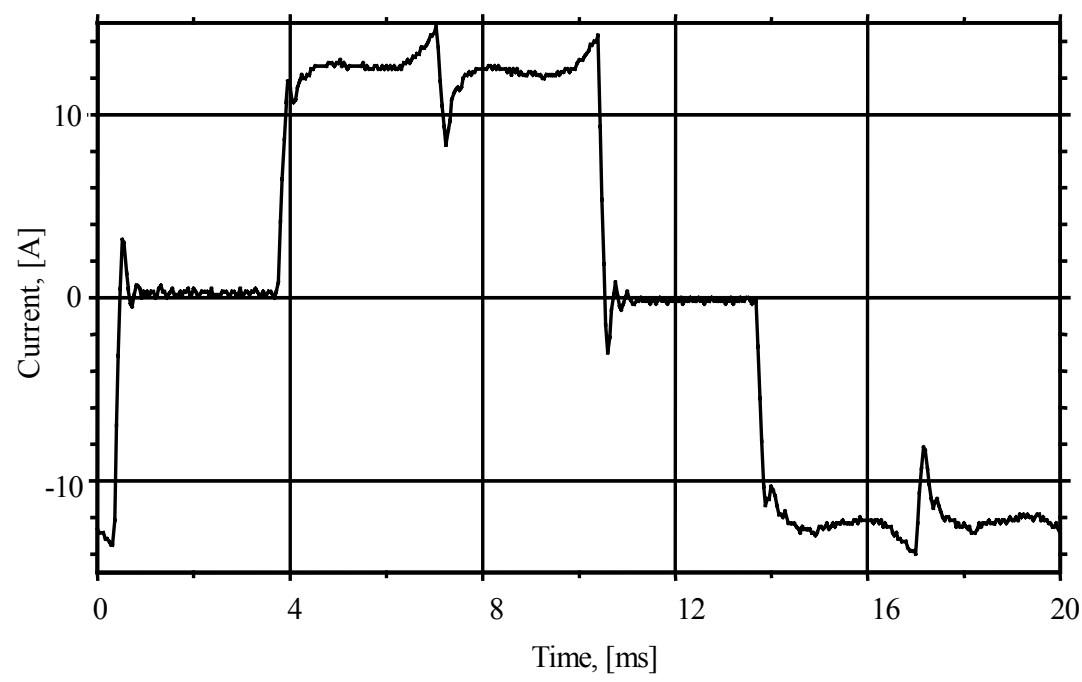

(a) Measured



(b) Simulated, Pspice

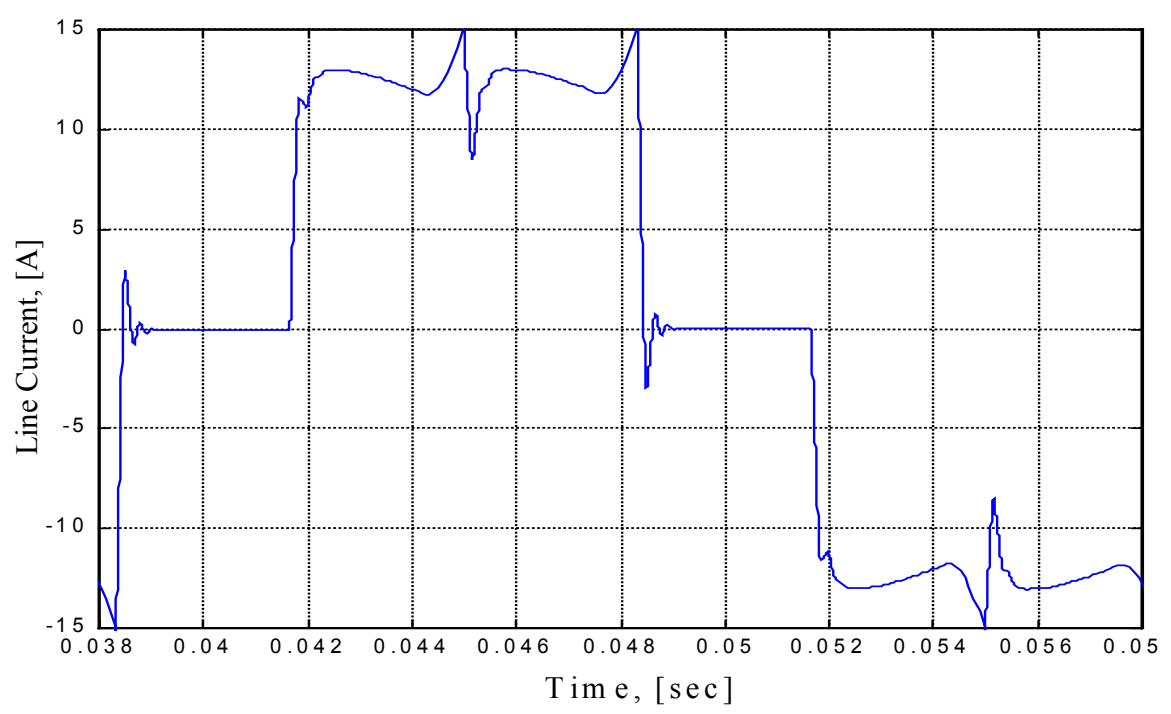

(C) Simulated, Matlab

Figure 11. Phase current waveforms with $\mathrm{T}_{1}=3.78 \mathrm{Nm}, 40.5 \mathrm{~V}$, speed $=1000$ r.p.m. 
AL-BADI and GASTLI

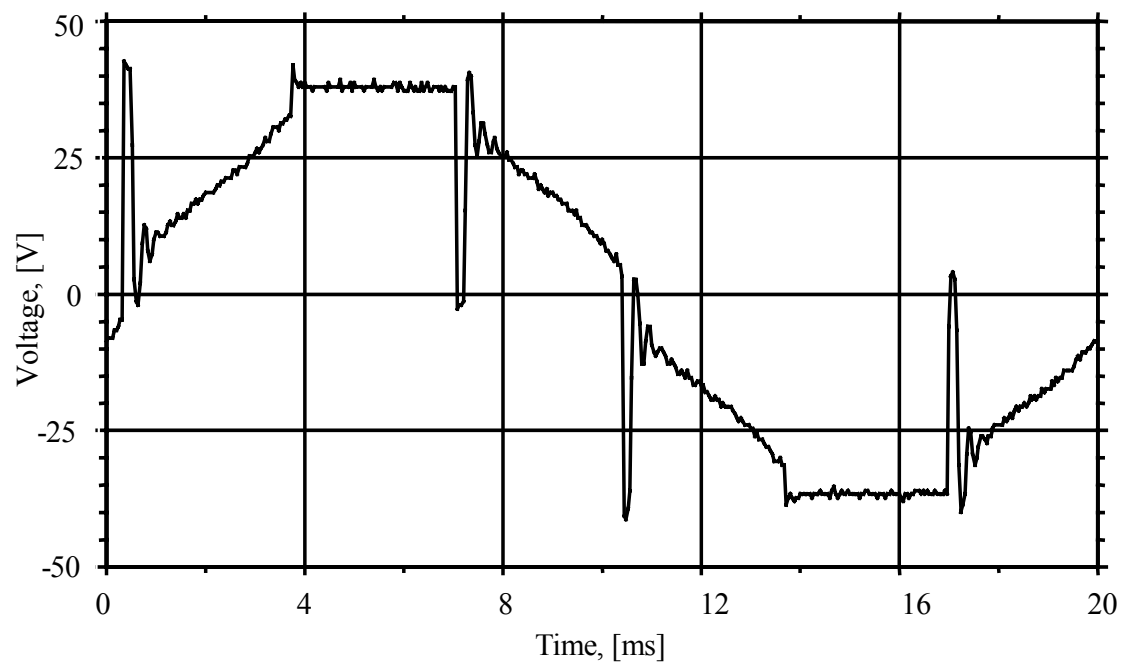

(a) Measured

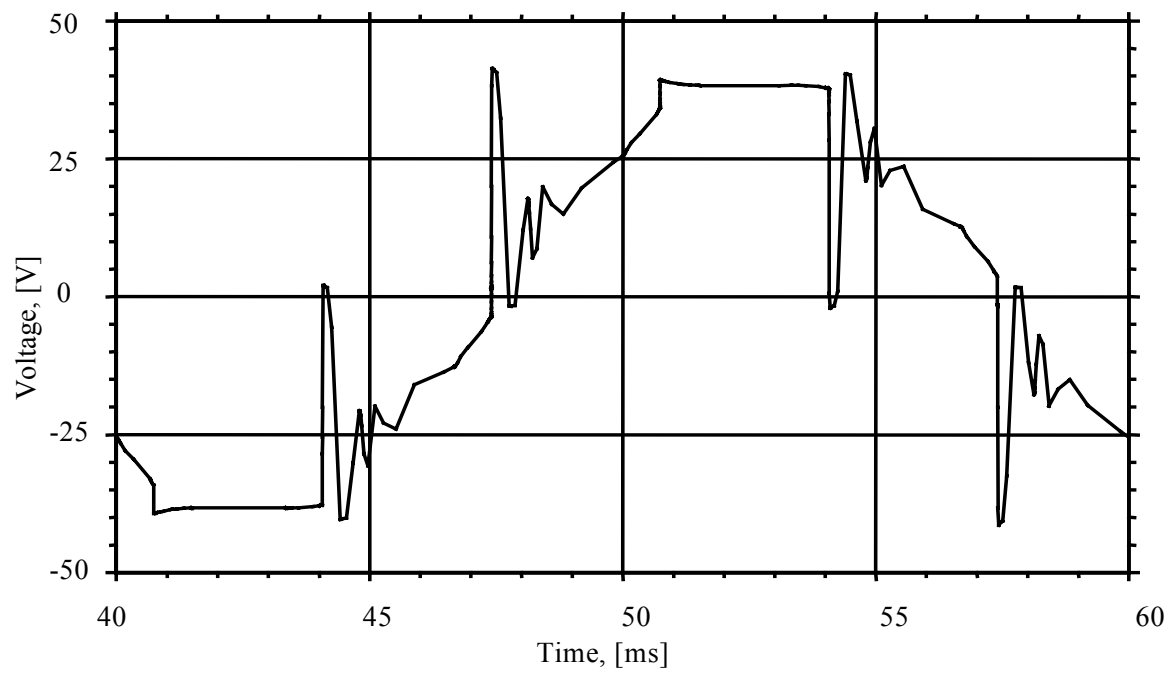

(b) Simulated, PSpice

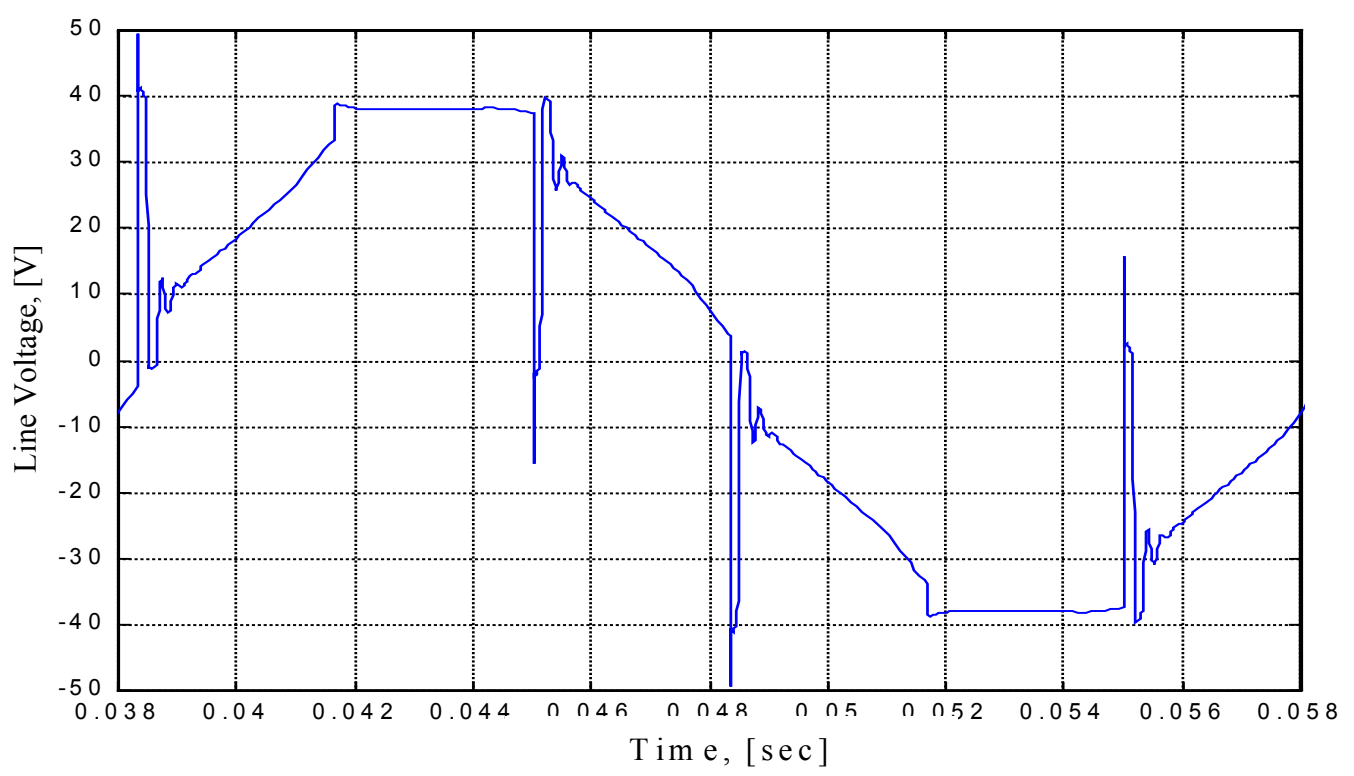

(c) Simulated, Matlab

Figure 12. Line voltage waveforms with $\mathrm{T}_{1}=3.78 \mathrm{Nm}, 40.5 \mathrm{~V}$, speed $=1000$ r.p.m. 
MATLAB AND PSPICE DYNAMIC MODEL

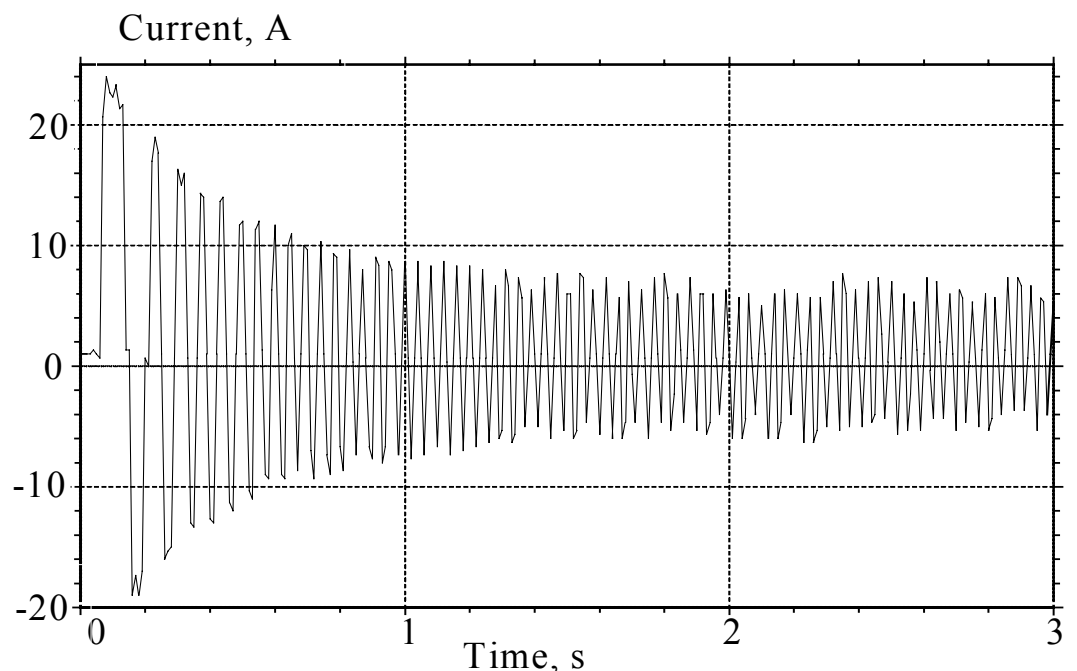

(a) Measured

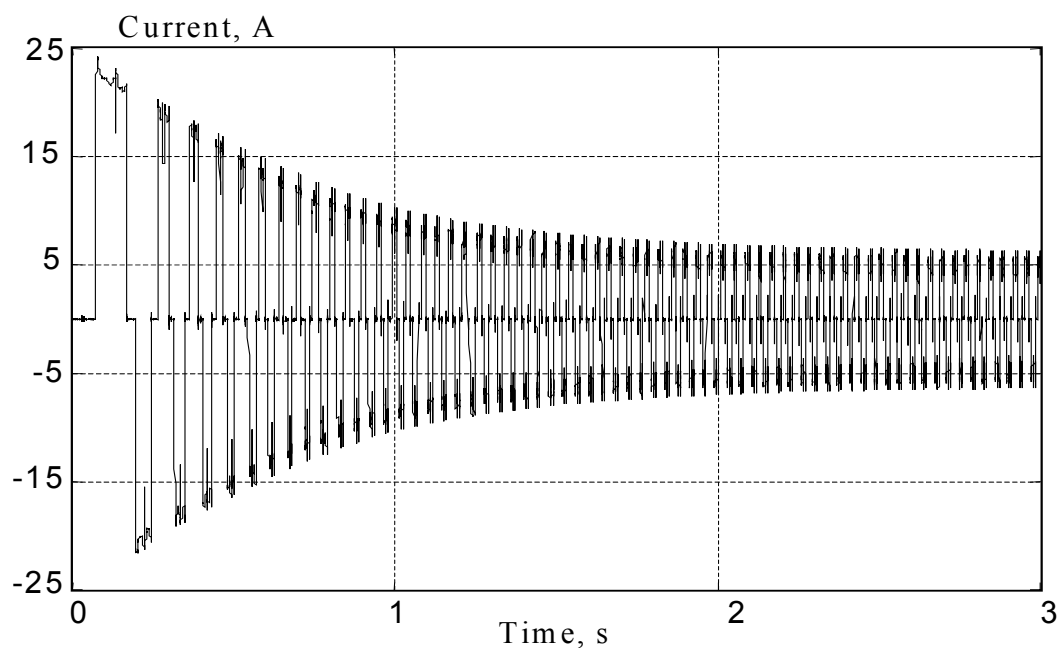

(b) Simulated, PSpice

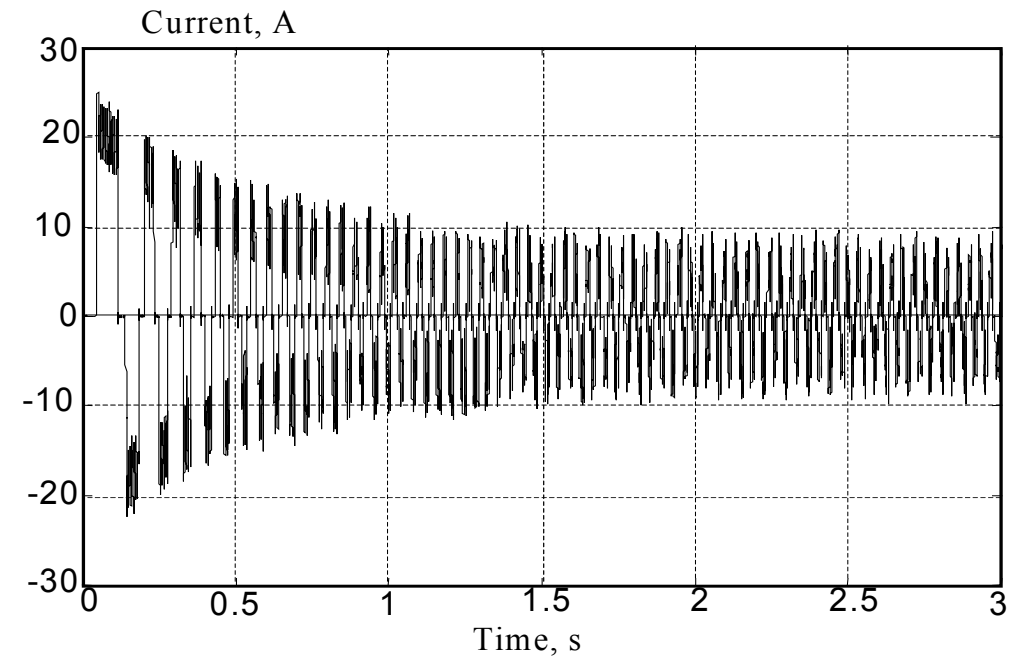

(c) Simulated, Matlab

Figure 13. Phase current transient. 
AL-BADI and GASTLI

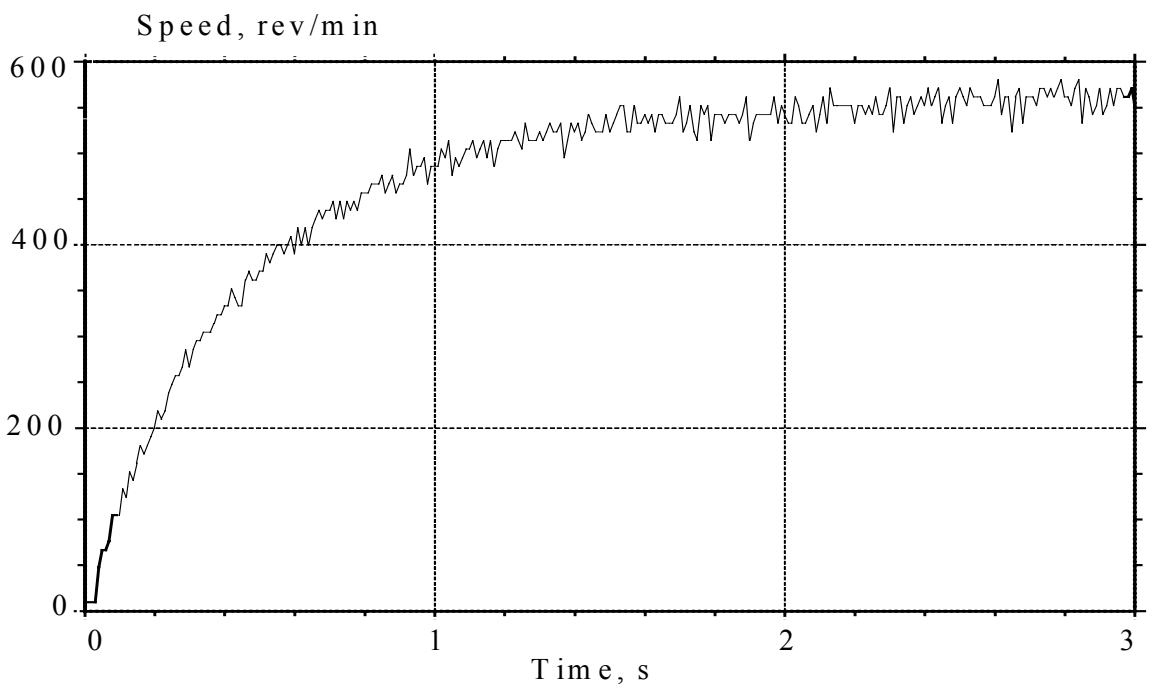

(a) Measured

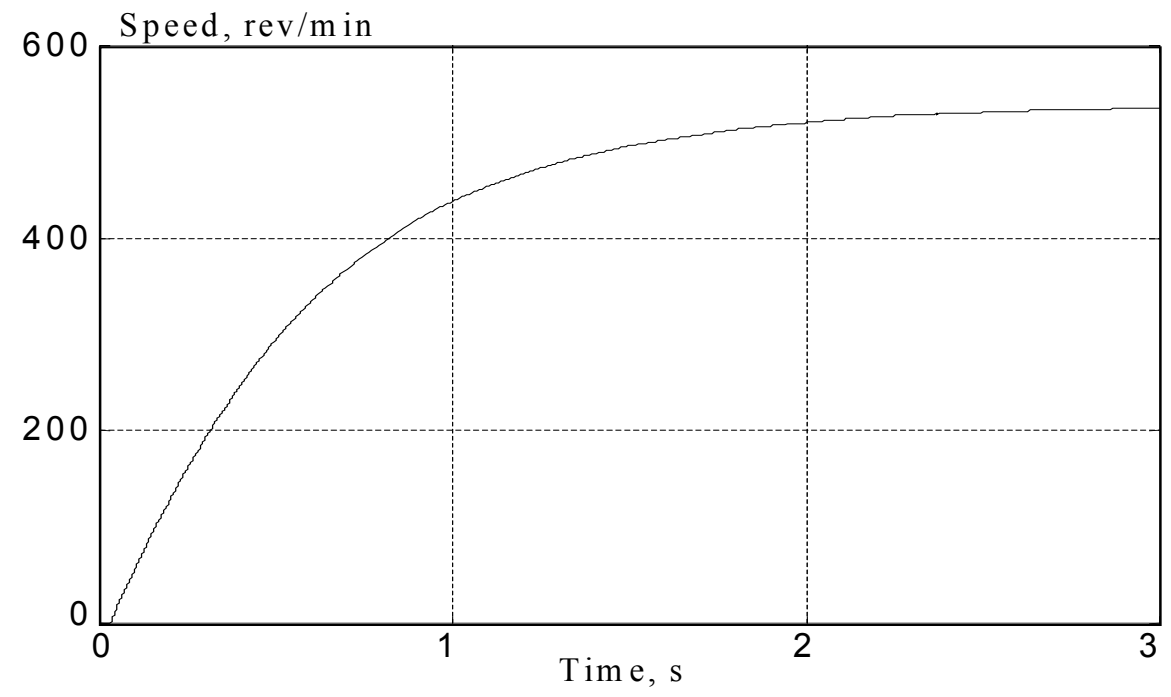

(b) Simulated, Pspice

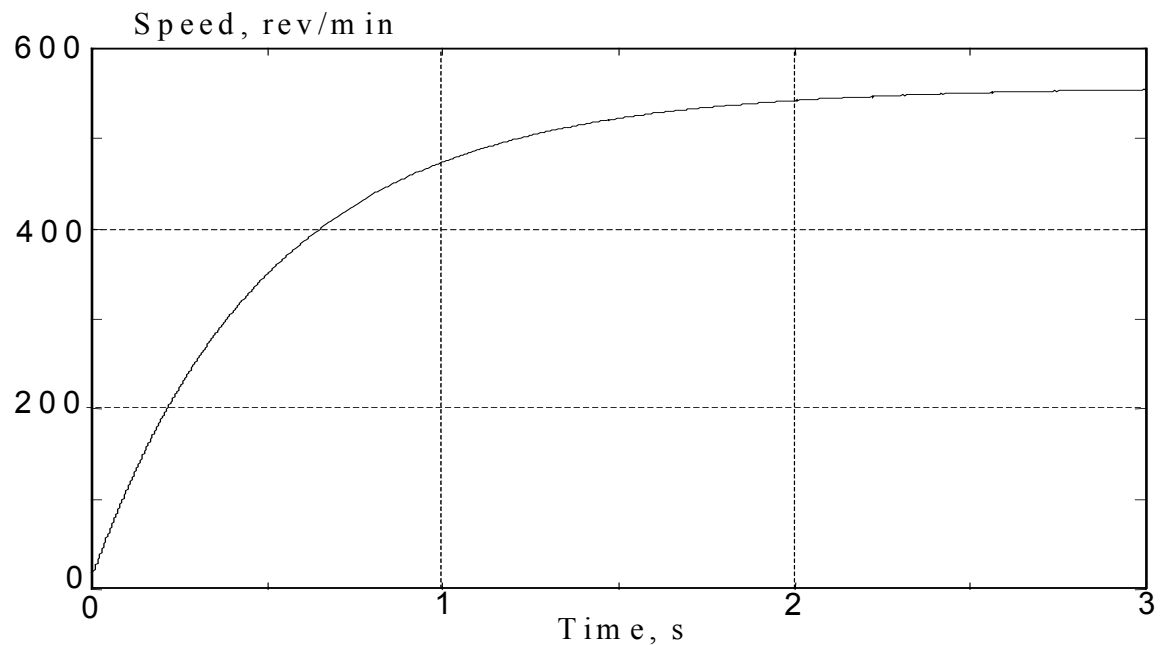

(c) Simulated, Matlab

Figure 14. Speed transient. 


\section{MATLAB AND PSPICE DYNAMIC MODEL}

\section{References}

AL-BADI, A.H and GREEN, A.M. 1998. A transient model of the Torus electrical machine using PSPICE. $33^{\text {rd }}$ Universities Power Engineering Conference, September 1998, Edinburgh, pp.254-257.

CHALMERS, B.J., GREEN, A.M., REECE, A.B. and AL-BADI, A.H. 1997. Modelling and simulation of the Torus generator. IEE Proc. B, Vol.144, 6: 446-452.

GASTLI, A., AKHERRAZ, M. and GAMMAL, M. 1998. Matlab/ Simulink/ANN Based Modeling and Simulation of A Stand-Alone Self-Excited Induction Generator. International Conference on Communication, Computer and Power, ICCCP'98, December 7-10 1998, Muscat, Sultanate of Oman, Sponsored by the IEEE and IEE, pp. 93-98.

GASTLI, A., AKHERRAZ, M. 1998. Matlab/Simulink Simulation of Variable-Speed BusbarConnected Self-Excited Induction Generator. International Conference on Communication, Computer and Power, ICCCP'98, December 7-10 1998, Muscat, Sultanate of Oman, Sponsored by the IEEE and IEE, pp. 258-263.

GREEN, A.M. and AL-BADI, A.H. 1997. Modelling and simulation of a Torus generator using PSPICE. $32^{\text {nd }}$ Universities Power Engineering Conference, September 1997, Manchester, pp.806-809.

Received 24 June 2001

Accepted 13 November 2001 